\title{
Trophic transfer in seagrass systems: estimating seasonal production of an abundant seagrass fish, Bairdiella chrysoura, in lower Chesapeake Bay
}

\author{
Kathryn L. Sobocinski ${ }^{1,2, *}$, Robert J. Latour ${ }^{1}$ \\ ${ }^{1}$ Virginia Institute of Marine Science, College of William \& Mary, PO Box 1346, Gloucester Point, VA 23062 USA \\ ${ }^{2}$ Present address: College of Earth, Ocean, and Atmospheric Sciences, Oregon State University, Corvallis, OR 97331, USA
}

\begin{abstract}
Silver perch Bairdiella chrysoura is a seasonally abundant fish in lower Chesapeake Bay seagrass habitats. Young-of-the-year fish recruit to these habitats in June and rear for the remainder of the summer before migrating to deeper habitats in the Bay and offshore as seawater cools in the fall. This species has been shown to be abundant in seagrass habitats, yet like many fishes in these habitats, little is known about its growth and production, and thus the contribution of this habitat type to overall production. We developed a bioenergetics model to estimate individual silver perch growth and calibrated this model using field-collected size data. Abundance data were used to develop a generalized additive model for predicting abundance over the simulation period (15 June to 15 October). We used the individual-based model output and estimated abundances to calculate total production. The calibrated bioenergetics model showed silver perch growth of approximately $0.19 \mathrm{~g} \mathrm{~d}^{-1}$ for total growth of $23.2 \mathrm{~g}$ over the simulation period. Peak abundance occurred in July with estimated values of 0.2 ind. $\mathrm{m}^{-2}$. The highest biomass was observed shortly after peak abundance. Total production for silver perch was estimated to be $22.9 \mathrm{~g} \mathrm{~m}^{-2}$ in the seagrass habitats measured. With an estimated 8100 ha of seagrass habitat in the lower Chesapeake Bay in 2010, silver perch contribute a considerable amount of biomass production. As an annually migrating species, silver perch export in excess of $7400 \mathrm{t}$ of biomass to the near-coastal ecosystem, providing a trophic subsidy from seagrass habitats via trophic transfer.
\end{abstract}

KEY WORDS: Seagrass - Trophic transfer - Secondary production - Fish habitat $\cdot$ Ecosystem subsidy $\cdot$ Bairdiella chrysoura $\cdot$ Bioenergetics

Resale or republication not permitted without written consent of the publisher

\section{INTRODUCTION}

Fish growth and production are of interest in the context of ecosystem functioning and fisheries management. For young-of-the-year (YOY) fishes, rapid growth is believed to be of paramount importance in reducing mortality, leading to strong year-classes and increased fisheries production (Houde 1987, 1989, Sogard 1997). In estuaries, where dynamic environmental conditions impact growth of fish larvae and juveniles, it is thought that newly recruited individuals reside in habitats that maximize the ratio of growth to mortality (Werner \& Gilliam 1984, Sogard 1992, Beck et al. 2001, Craig et al. 2006, Grol et al. 2014). For this reason, many YOY fishes have been shown to prefer structured habitats, such as seagrasses and oyster reefs, to unstructured habitats (Orth et al. 1984, Mattila et al. 1999, Heck et al. 2003). While food availability is one factor accounting for the high densities of fishes and decapods in seagrass beds (Ryer 1987, Virnstein \& Howard 1987, Fredette et al. 1990), many species are thought to rely on the habitat for refuge from predation instead, invoking a trade-off between growth and mortality. 
For example, results of a field growth experiment for Gobiosoma bosci demonstrated that some fish sacrificed growth potential by residing in seagrass beds, which afforded predation refuge due to their structural complexity (Sogard 1992). Thus, high densities of finfishes in seagrass habitats may be due in part to their function as a refuge (Gillanders 2006, Froeschke \& Stunz 2012), especially for juvenile fishes subject to high predation mortality. As such, these habitats have been shown to be important rearing habitats for many species of fishes, yet little is known about how production from these habitats supports nearby coastal ecosystems.

Resource managers are interested in the value of habitats, both in terms of economics (Costanza et al. 1997, Barbier et al. 2011, Liquete et al. 2013) and in terms of biological needs and reference points for species or guilds (Seitz et al. 2014). Despite this management interest, the value of a particular habitat to a given species or to production of a guild has not been well described for many regions and species, especially for fishes in open marine systems. However, recent studies have shown that seagrassproduced fish biomass can subsidize offshore fish populations extensively when fish migrate from the habitat (Nelson et al. 2012, 2013). While there is evidence that seagrass habitats are used extensively by fishes, the overall contribution to production and population viability is less explicit (Heck et al. 2003, Jones 2014). In Chesapeake Bay, little is known about how seagrass habitats influence the growth and production of fishes - which are often YOY individuals or smaller fishes of little commercial importance-using seagrasses for rearing (but see Smith et al. 2008). Additionally, recent warm summers in this region have led to die-offs of the dominant seagrass species Zostera marina (Moore \& Jarvis 2008), and the impacts of such large-scale habitat loss to YOY fishes and to greater coastal fish populations are unknown.

In the lower Chesapeake Bay, silver perch Bairdiella chrysoura (Lacépède) is a numerically abundant sciaenid found in seagrass habitats during the summer months (Orth \& Heck 1980, Schaffler et al. 2013, Sobocinski et al. 2013). Silver perch recruit to these habitats in late June, reside throughout the warm summer months, and migrate to deeper habitats in September as the water cools. This life-history pattern is exhibited by many sciaenid fishes in Chesapeake Bay, in large part because the Bay experiences relatively cold winter water temperatures $\left(0\right.$ to $\left.5^{\circ} \mathrm{C}\right)$. While much work has been done on the feeding and morphology of silver perch (Chao \&
Musick 1977, Brooks 1985, Waggy et al. 2007) less information exists regarding growth, survival, and migration. Being abundant along the Atlantic and Gulf of Mexico coasts, silver perch has been shown to be a prey species for a number of large fishes and mammals, including bluefish Pomatomus saltatrix, spotted seatrout Cynoscion nebulosus, summer flounder Paralichthys dentatus, sharks, and dolphins (Allen et al. 2001, Ellis \& Musick 2007, K. L. Sobocinski unpubl. data), potentially contributing to energy transfer between shallow seagrass habitats and deeper estuarine and marine waters. Thus, as a model species for seagrass habitat use, understanding the growth, abundance, and mortality of silver perch in these habitats is important for understanding the value of seagrasses in terms of fish production and the role this species and the habitat type play within the larger Bay food web.

Determining growth can be challenging in both field and laboratory settings. Fish movement and the difficulty of recapturing the same individual make observing growth in the field difficult (but see Laslett et al. 2004). Similarly, tracking a cohort through time can be problematic when fish are sequential spawners and differentiation between cohorts is unclear; difficulties also arise toward the end of the growth period, where differential growth will expectedly lead to greater variation in the observed lengths (Rooker \& Holt 1997). Feeding and growth studies in the lab are also troublesome, as replicating the dynamic environmental and foraging conditions of an estuary is challenging, and external factors that influence predation (e.g. competition, predation) are often omitted from the laboratory set-up. Thus, a modeling approach is one solution, whereby lab and field data can be combined to arrive at a more accurate picture of fish growth.

Bioenergetics modeling uses a mass-balance approach based on the balanced energy equation from Winberg (1956), where growth is only possible once costs of metabolism have been met. Bioenergetics models have been successfully applied to model fish feeding and growth (Kitchell et al. 1977, Hartman \& Brandt 1995a,b, Hanson et al. 1997). Sub-equations for consumption and metabolic costs, which relate to fish size and ambient temperature, aid in modeling growth, given that temperature is often a controlling factor for fish physiology (Fry 1971). Depending on the question of interest, the equation can be reorganized to model consumption with growth as an input (Kitchell et al. 1977, Hanson et al. 1997). Sensitivity analysis of bioenergetics models have shown that they generally provide robust estimates of fish 
growth and consumption (Stewart et al. 1983, Luo \& Brandt 1993, Hartman \& Brandt 1995a,b). Furthermore, bioenergetics models can be particularly useful when scaled to populations (Luo \& Brandt 1993, Latour et al. 2003), thus taking advantage of available field data on abundance.

Given the abundance of silver perch in seagrass habitats in the estuary and their evident seasonal growth, a better understanding of their energetic requirements, resource demands, and overall production enables an estimation of the value of seagrass habitats in terms of biomass production for this species. Using silver perch as a model species, we aimed to (1) develop a working bioenergetics model with which to estimate growth; (2) use observations of fish size from the field to calibrate our bioenergetics model; (3) test model sensitivity to parameter values, feeding intensity, and temperature; and (4) estimate overall production using field-based abundance estimates from a representative seagrass bed to make inferences regarding habitat productivity for consumers such as silver perch. We combined the individual-based model (bioenergetics model) with models of abundance to assure field-based measurements of growth were realistic, given the potential for individuals from multiple cohorts being collected on one sampling date. We expected silver perch would have comparable first-year growth rates to sympatric species exhibiting similar life history strategies, such as spot Leiostomus xanthurus (Pacheco 1962) and weakfish Cynoscion regalis (Hartman \& Brandt 1995b). However, as silver perch show greater habitat preference for seagrass beds, they more directly connect production to this specific habitat type. The combination of fieldbased analysis and modeling in this study serves to portray a representative picture of the production of juvenile silver perch in an important juvenile habitat.

\section{MATERIALS AND METHODS}

\section{Study sites}

All fieldwork was conducted in the polyhaline region near the mouth of the York River in lower Chesapeake Bay, USA. Silver perch abundance and distribution data were collected at 3 sites representative of lower Chesa- peake Bay seagrass beds: Browns Bay, Goodwin Island, and Pepper Creek (Fig. 1). The Goodwin Island site is within the Chesapeake Bay National Estuarine Research Reserve (NERR), and was chosen in part for the availability of complementary continuous water quality data, including water temperature.

\section{Field collection}

To describe abundance of silver perch, fishes were captured using a $4.9 \mathrm{~m}$ otter trawl towed from a shallow-draft vessel, during high tides both day and night from May to September 2010. Samples were collected biweekly at each site, with higher sampling frequency during peak abundance. Each tow was 2 min in duration with 6 replicate tows taken at each site on each sampling day, and each tow was nonoverlapping. Tow length, boat speed-over-ground and direction were recorded with a high precision GPS unit (Trimble GeoXT 2005 Series) to allow for estimation of area swept. Therefore, relative abundance was defined as density, in numbers of fish per area swept, per tow.

Fish were brought onboard and identified, enumerated, and a subset measured (total length, TL) in the field before being released back to the water. A smaller subset of fish was put on ice and taken back to the lab for further analysis, including length measurement, wet weight measurement, and stomach extraction for later gut-content analysis. Data were entered

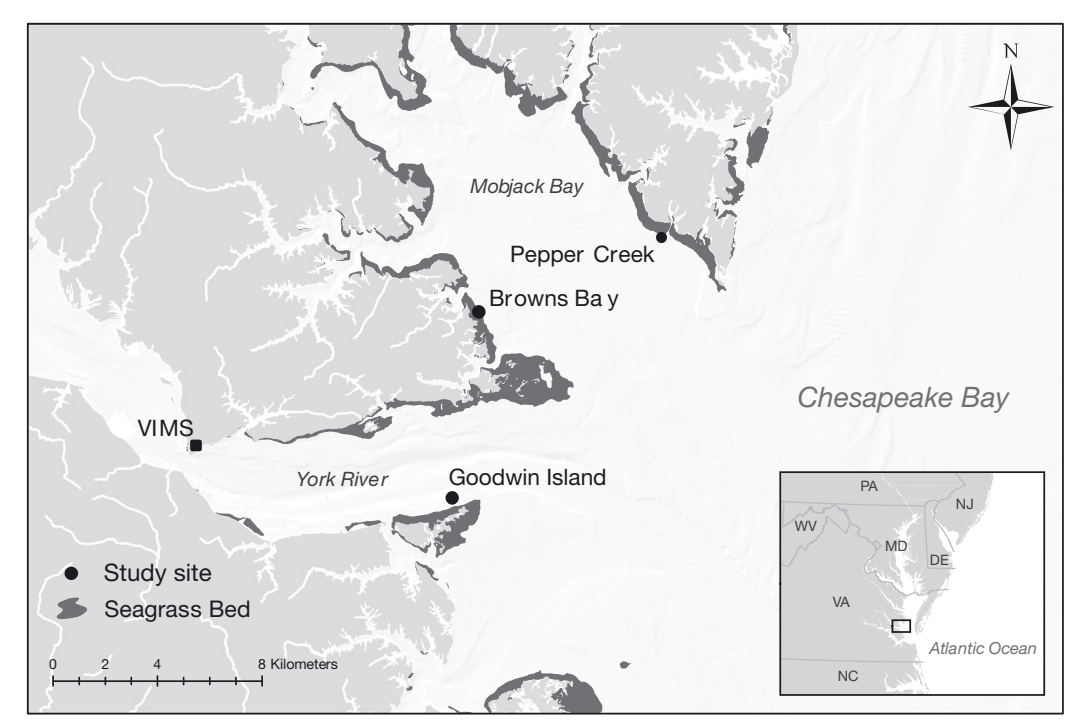

Fig. 1. General study area at the mouth of the York River in Chesapeake Bay, Virginia, USA (inset) and study sites and seagrass coverage from the Virginia Institute of Marine Science (VIMS) Submerged Aquatic Vegetation Program for 2010 
on field datasheets and transferred into a spreadsheet once in the lab. All input field data were checked for accuracy by a second researcher. To generate biomass data for the fish collected, a length-weight regression was developed for the silver perch from this study using the subset of fish that were measured in the lab. This relationship was based upon 2010 YOY fishes only (e.g. starting in June with fish that were $<30 \mathrm{~mm}$ TL). This relationship was used for conversions between length and biomass.

Water quality parameters, including temperature $\left({ }^{\circ} \mathrm{C}\right)$, dissolved oxygen $\left(\mathrm{mg} \mathrm{l}^{-1}\right)$, and salinity (ppt), were measured once from mid-water in between trawls at a given site on a sampling day. Additionally, daily means were compiled from the Virginia Estuarine and Coastal Observing System (VECOS) autonomous sensor CHE019.38, located at the Goodwin Island NERR site (http://web2.vims.edu/vecos/). Data collected at the time of fish sampling were compared to the VECOS sensor data to ensure those measurements were representative.

\section{Bioenergetics model}

To address our questions related to individual YOY growth, we used the Wisconsin bioenergetics model (Kitchell et al. 1977, Hewett \& Johnson 1992, Hanson et al. 1997) as a framework. The 'Wisconsin Model' utilizes a mass-balance approach that has been widely used to model consumption and/or growth of fishes under various environmental conditions (Hanson et al. 1997). While this model has been used for modeling applications for several species in Chesapeake Bay, such as bay anchovy Anchoa mitchilli (Luo \& Brandt 1993), striped bass Morone saxatilis, bluefish and weakfish (Hartman \& Brandt 1995a), and Atlantic croaker Micropogonias undulatus (Nye 2008), it has not been used for silver perch, although earlier laboratory work on energy utilization of silver perch formed the basis of our model (Brooks 1985).

The bioenergetics model is based on an energy budget where specific growth rate, $\mathrm{d} B / B \mathrm{~d} t$ is modeled as:

$$
\frac{\mathrm{d} B}{B \mathrm{~d} t}=C-(R+F+U)
$$

where $B$ is the biomass of the fish (typically in $g$ wet wt), $t$ the model time step (typically $1 \mathrm{~d}$ ), $C$ is consumption, $R$ is respiration, $F$ is egestion, and $U$ is excretion. Using previous studies of silver perch feeding and metabolic processes (Adams 1976, Brooks 1985, Ayala-Pérez et al. 2006, Grammer et al. 2009) along with bioenergetics models for similar species, life history stages, and habitats (Kitchell et al. 1977, Hartman \& Brandt 1995a, Madon et al. 2001, Stevens et al. 2006, Nye 2008), we compiled data for parameterizing the model. All model (descriptions and values) are provided in Table 1.

\section{Consumption}

$C\left(\mathrm{~g} \mathrm{~g} \mathrm{~g}^{-1} \mathrm{~d}^{-1}\right)$ was modeled as a function of fish weight $(W, g)$, temperature $\left({ }^{\circ} \mathrm{C}\right)$, and feeding, where:

$$
C=C_{\max } \times f\left(T_{C}\right) \times p
$$

and

$$
C_{\max }=C A \times W^{\mathrm{CB}}
$$

The term $C_{\max }$ relates maximum consumption to body mass at the optimum temperature. $C$ is the actual consumption rate and is defined as the maximum consumption adjusted by a temperature function, $f\left(T_{C}\right)$, and the proportion $(p)$ of maximum consumption realized in the field $(0<p<1)$, where $p$ is a proxy for food availability. $C A$ and $C B$ are the intercept and slope of the allometric mass function, respectively. We used the consumption temperature function for warmwater fishes (consumption Eq. 2 in Hanson et al. 1997):

$$
\left.f\left(T_{\mathrm{C}}\right)=V^{X} \times \mathrm{e}^{X(1-V)}\right]
$$

where

$$
\begin{gathered}
V=(C T M-T) /(C T M-C T O) \\
Z=\ln (C Q) \times(C T M-C T O) \\
Y=\ln (C Q) \times(C T M-C T O+2) \\
X=\left\{Z^{2} \times\left[1+(1+40 / Y)^{0.5}\right]^{2}\right\} / 400
\end{gathered}
$$

and $C Q$ is an approximation of the rate at which the function increases with temperature $\left(Q_{10}\right), C T O$ is the temperature of optimal consumption, and CTM is the temperature above which consumption ceases. Daily mean temperatures from the Goodwin Island field site were used as input. We used data on ration for different weights of silver perch $(2,6$, and $13 \mathrm{~g})$ at varying temperatures $\left(20,24\right.$, and $\left.28^{\circ} \mathrm{C}\right)$ from Brooks (1985) and adjusted the $C A$ and $C B$ parameters to correspond with the lab-observed optimal and maximum rations from that study. We estimated CTM because we lacked lab data for consumption above $28^{\circ} \mathrm{C}$, but fish 20 to $200 \mathrm{~mm}$ at 34 to $37^{\circ} \mathrm{C}$ reached $\mathrm{LD}_{50}$ after $3 \mathrm{~h}$ (Pattillo et al. 1997 and references therein). Thus, we set $C T M$ to $32^{\circ} \mathrm{C}$, presuming that consumption would cease well before lethal temperatures were experienced (Elliott \& Persson 1978); 
Table 1. Bioenergetics model parameters for silver perch Bairdiella chrysoura

\begin{tabular}{|c|c|c|}
\hline Parameter & Description & Parameter value \\
\hline \multicolumn{3}{|c|}{ Consumption $(C)\left(\mathrm{g} \mathrm{g}^{-1} \mathrm{~d}^{-1}\right)$} \\
\hline$C A$ & Intercept for maximum consumption & 0.3 \\
\hline$C B$ & Exponent for maximum consumption & -0.25 \\
\hline$C Q$ & Slope for consumption temperature-dependence function & 1.78 \\
\hline CTO & Optimum temperature for consumption & 27 \\
\hline CTM & Maximum temperature for consumption & 32 \\
\hline \multicolumn{3}{|c|}{ Respiration $(R)\left(\mathrm{g} \mathrm{O}_{2} \mathrm{~g}^{-1} \mathrm{~d}^{-1}\right)$} \\
\hline$R A$ & Intercept for standard respiration & 0.0016 \\
\hline$R B$ & Exponent for standard respiration & -0.2 \\
\hline$R Q$ & Slope for respiration temperature-dependence function & 0.08 \\
\hline$A C T$ & Activity multiplier & 1.25 \\
\hline$S D A$ & Specific dynamic action coefficient & 0.172 \\
\hline \multicolumn{3}{|c|}{ Egestion $(F)$ and excretion $(U)$} \\
\hline FA & Proportion of consumed food egested & 0.117 \\
\hline$U A$ & Proportion of assimilated food excreted & 0.06 \\
\hline \multicolumn{3}{|c|}{ Caloric densities ( $\mathrm{J} \mathrm{g}^{-1}$ wet weight) } \\
\hline $\mathrm{O}_{2}$ Conversion & Conversion of $1 \mathrm{~g} \mathrm{O}_{2}$ to $\mathrm{J}$ & 13556 \\
\hline $\begin{array}{l}\text { Predator energy } \\
\text { density }(P E D)\end{array}$ & $\mathrm{J}=3910.3 \times W^{0.1431}$, where $W=$ wet weight in $\mathrm{g}$ & $\begin{array}{l}W=0.1 \mathrm{~g}, P E D=2800 \mathrm{~J} \mathrm{~g}^{-1} \\
W=12 \mathrm{~g}, P E D=5600 \mathrm{~J} \mathrm{~g}^{-1}\end{array}$ \\
\hline \multirow[t]{5}{*}{ Prey energy density } & Predator size; diet & \\
\hline & $<0.25 \mathrm{~g}_{\text {; }}$ mainly copepods & $2900 \mathrm{~J} \mathrm{~g}^{-1}$ \\
\hline & $0.25-1 g_{\text {; }}$ mixed copepods, amphipods, mysids & $3600 \mathrm{~J} \mathrm{~g}^{-1}$ \\
\hline & 1-10 g; mixed mysids, amphipods, shrimp & $4000 \mathrm{~J} \mathrm{~g}^{-1}$ \\
\hline & $>10 g_{\text {; }}$ mixed mysids, shrimp, amphipods, fish & $4500 \mathrm{~J} \mathrm{~g}^{-1}$ \\
\hline Temperatures $\left({ }^{\circ} \mathrm{C}\right)$ & Min. $=23.2, \max .=30.3$, mean $=27.0$ & \\
\hline
\end{tabular}

$32^{\circ} \mathrm{C}$ was the maximum temperature experienced by fish in the field during our study.

\section{Respiration}

The respiration term $R\left(\mathrm{~g} \mathrm{O}_{2} \mathrm{~g}^{-1}\right.$ fish $\left.\mathrm{d}^{-1}\right)$ was modeled as a function of wet weight and temperature, where an exponential relationship describes the temperature dependence:

$$
R=R A \times W^{\mathrm{RB}} \times \mathrm{e}^{(\mathrm{RQ} \times T)} \times A C T
$$

In this equation, $R A$ and $R B$ are the intercept and slope of the relationship between fish body weight $(W$ in $g$ wet weight) and the standard respiration rate (Table 1). The temperature dependence function $\mathrm{e}^{(R Q \times T)}$ uses $R Q$ as an approximation of $Q_{10}$ and daily temperature (respiration Eq. 1 in Hanson et al. 1997). ACT is an activity coefficient that accounts for fish movement. This value has been set to 1 when fish swimming speed is constant (Kitchell et al. 1977, Hanson et al. 1997), but is likely between 1 and 3 for most standardenergy-demand fishes. We set this value to $1.25,25 \%$ above the standard level (Madon et al. 2001).
The other respiration component consists of the equation including specific dynamic action $(S D A)$, defined to be the cost associated with processing food:

$$
S=S D A \times(C-F)
$$

The quantity $S$ was estimated as $S D A$ multiplied by consumption minus the specific egestion rate $\left(F, \mathrm{~g} \mathrm{~g}^{-1}\right.$ $\mathrm{d}^{-1}$, see next section).

\section{Waste losses}

Both egestion rate and excretion rate $(U)$ were modeled as constant proportions of consumption and assimilation, respectively:

$$
\begin{gathered}
F=F A \times C \\
U=U A \times(C-F)
\end{gathered}
$$

Both FA and $U A$ (the proportion of food egested and excreted, respectively) for the silver perch model were based on Brooks (1985) and are similar to values used in other models (Hartman \& Brandt 1995a, Madon et al. 2001). 


\section{Energy density}

Model calculations are typically made in energy units ( $\mathrm{J}$ or calories) with resulting estimates converted to mass ( $g$ wet weight; Ney 1993). As such, 2 other important components of the model are the energy densities $\left(\mathrm{J} \mathrm{g}^{-1}\right)$ for both the predator (silver perch) and prey. The predator energy density was modeled as a function of fish weight, as it has been shown to increase with fish size (Hartman \& Brandt 1995c). We used values reported by Wuenschel et al. (2006) and Hartman \& Brandt (1995c) to arrive at a relationship for silver perch energy density $(\mathrm{J})$ and wet weight:

$$
\text { Energy density }=3910.3 \times W^{0.1431}
$$

Energy density of $5650 \mathrm{~J} \mathrm{~g}^{-1}$ was previously reported (Brooks 1985), which corresponds to a $13 \mathrm{~g}$ fish using our relationship.

Prey energy density was determined by diet analysis undertaken as part of this study in conjunction with energy density values for prey items reported elsewhere (Cummins \& Wuycheck 1971, Luo \& Brandt 1993, Hartman \& Brandt 1995b). We analyzed the diets of 75 silver perch ranging in size from 22 to $146 \mathrm{~mm}$ (TL). Of those, 13 had empty stomachs and the remaining individuals $(n=62)$ were found to consume a variety of prey from gammarid amphipods to fishes, with mysid shrimp being the most common prey type. Previous studies (Chao \& Musick 1977, Brooks 1985, Waggy et al. 2007) have shown 3 basic feeding guilds: $<40 \mathrm{~mm}$ TL fish, copepods and amphipods; 40 to $70 \mathrm{~mm} \mathrm{TL}$, mysids and crangon shrimp; and $>70 \mathrm{~mm} \mathrm{TL}$, diverse diet of invertebrates and fishes. Using multivariate analysis (non-metric multidimensional scaling [NMDS] and ANOSIM for exploration of group differences) we found the fish in our study followed similar feeding patterns, with the exception of fish between 70 and $90 \mathrm{~mm}$ TL continuing to eat primarily mysids and shifting to a predominately fish diet once greater than $90 \mathrm{~mm}$ TL. We based our prey energy densities on these feeding guilds for specific fish weight, using the lengthweight regression developed in this study.

Temperature inputs to the model were the daily means from the VECOS sensor near Goodwin Island. The output from the bioenergetics model was an estimate of growth over the summer season for an individual silver perch. The simulation period (122 d) spanned the time of silver perch residence in seagrass habitats, roughly 15 June to 15 October based on $3 \mathrm{yr}$ of observational field data (Sobocinski et al. 2013, K. L. Sobocinski unpubl. data).

\section{Sensitivity analyses}

Bioenergetics models have been shown to be most sensitive to components of the consumption and respiration equations (Bartell et al. 1986), and we selected parameters from these equations $(C A, C B, R A$, $R B, R Q$ ) for manipulations to understand model sensitivity. We used individual parameter perturbations to investigate parameter sensitivity (Kitchell et al. 1977, Bartell et al. 1986). We followed the rationale in Bartell et al. (1986) for levels of disturbance, using coefficients of variation (CVs) of 2,10, and $20 \%$ for the variation added to each parameter. Each parameter was manipulated individually by drawing a random value from a normal distribution centered on the nominal parameter values in the model (e.g. $C A=0.3$, mean $=0.3$ ). We conducted 1000 simulations and collected the modeled daily growth and input parameter values for each run. The mean squared error (MSE) across all simulations, using the calibrated model (see below) as the observed and the simulation run as the predicted value, was used to rank the sensitivity of the permuted parameters, with parameters with higher MSE being deemed more sensitive.

We conducted an additional error analysis to assess the sensitivity of the model to values for the $p$ term, which has been shown to strongly influence model behavior (Bartell et al. 1986). Permuted values were drawn from a normal distribution centered on the nominal value for each day, as in the parameter perturbation, with the same 3 levels of variation. In addition to evaluating differences in growth with the varying levels of added error, we used the output from the error analysis to determine how production would change, given the growth observed with varying levels of $p$. Thus, variation in growth was propagated through the production estimations using the values for the upper and lower confidence limits for growth. This analysis showed how model uncertainty would influence our calculations of overall production.

Because temperature is so important to fish physiology, we applied the calibrated bioenergetics model (see below) to estimate how an increase in seawater temperature of $1{ }^{\circ} \mathrm{C}$ impacted fish growth. This magnitude of increase in water temperature has been observed in Chesapeake Bay over recent decades (Najjar et al. 2010, Sobocinski et al. 2013) and the warming trend is not expected to reverse. While silver perch is a warm-water species, the metabolic costs of increasing water temperature are likely to impact growth and/or consumption. We added $1^{\circ} \mathrm{C}$ to the 2010 temperatures we used in model development and estimated fish growth under the revised tempera- 
ture regime using the calibrated model to determine growth sensitivity to increasing temperature.

\section{Observed data analysis}

\section{Growth}

To calibrate the bioenergetics model, we compared the model output (fish growth) to observed data from field collections. To this end, all length data (those measured in the field and those measured in the lab) and the associated collection dates were assembled. Histograms of length frequency for each sampling date, daily modes, existing life history and growth information, and plots of densities, weights, and lengths were used to define a probable cohort from each field site. We broke the dataset down by site for this analysis, as movement among sites is unlikely; once settled, it is thought that silver perch remain in a juvenile habitat for the duration of the season (Rooker et al. 1998). The cohorts for each site were used in developing field-based growth models. Fish of spawning size appeared in the catch dataset in May and early June, but these individuals were rare after that time. Thus, catches from late June through September were comprised almost entirely of YOY individuals (K. L. Sobocinski pers. obs.).

We developed linear (Weight $\sim$ Date), exponential [Weight $\sim a \times \exp ($ Date $\times b)$ ], and Gompertz \{Weight $\sim a \times \exp [b \times \exp ($ Date $\times c)]\}$ growth models for each site and for all sites combined. In all models, fish weight (g) was the response variable. All modeling was done using functions ' $\mathrm{lm}$ ' (for linear regressions) and 'nls' (for exponential and Gompertz fits) in R (R Development Core Team 2013). Akaike's information criterion (AIC) was used to select the best fitting model (Burnham \& Anderson 2002). We used plots of residuals for model validation and to address assumptions using the diagnostics in the 'nlstools' package. A predicted growth trajectory was developed for the $122 \mathrm{~d}$ simulation period, based on the best fitting model. We evaluated site models and did not find evidence of statistical differences among sites, but we noted increased variance at later dates. We thus generated an overall model from pooled site data as a representative case.

The observed growth model was then compared to bioenergetics output. We first used a visual comparison of estimated growth to determine gross differences between the models. We then generated sums of squares for the observed minus the predicted growth and minimized this value by optimizing $p$ in the bioenergetics model to reproduce the fit of the observed data. The parameter $p$ is suitable for optimization because it is highly sensitive and it cannot easily be measured directly in the field (Bartell et al. 1986). Our model exploration showed that growth over the model period varied considerably with differing values of $p$, from negligible growth at $p=0.2$ (constant) to unrealistic growth for this species (60 g over $122 \mathrm{~d}$ ) with $p=0.8$ (constant). We first ran the optimization unconstrained to assess overall fit. We then constrained the model to acceptable input values for $p(0<p<$ 1). By optimizing $p$ to meet observed growth, we were able to assess the validity of the base bioenergetics model growth estimate. We then calibrated the model to the field data using the adjusted values for $p$. This calibrated model became the working model.

Abundance estimates

We modeled fish abundance over the summer season, based on our field data collection, using generalized additive models (GAMs). GAMs allow for a flexible modeling approach where non-linearities in the relationships between response and explanatory variables exist. Responses can be modeled with both a parametric component (equivalent to generalized linear modeling) and also with a non-parametric component, which relies on smoothing functions for covariates (Wood 2006, Zuur et al. 2009, Zuur 2013). These relationships are driven by the data and not by a priori assumptions of relationships among the response and predictor, which in this case appeared to be quadratic in nature based upon exploration with generalized linear models (Zuur et al. 2009).

The 'gam' function in 'mgcv' package in R (R Development Core Team 2013) was used for all GAM modeling. The 'gam' function estimates the optimal smoothed relationship in model fitting. Effective degrees of freedom ('edf') is a calibration tool to determine the shape of the curve, where a value of 1 indicates a straight line and a value of 10 a highly non-linear pattern (Zuur 2013). The smoothers used in this application were thin plate regression splines for all parameters except date, where we used a cubic regression spline to account for similarities between the endpoints (Zuur 2013). The models were fitted using the 'GCV.Cp' method and best models were re-estimated by 'REML' to check for stability.

In all cases, the response variable was the logtransformed density of silver perch (no. $\mathrm{m}^{-2}$ ) and the predictor variables of interest were date (modeled as day of the year, DOY), site (3 sampling sites), and the 
water quality parameters temperature, salinity, and dissolved oxygen. The full model form was:

$$
\begin{aligned}
\text { Density }_{i}= & a+b_{1} \text { site }+s_{1}(\text { date })+ \\
& \left.s_{2} \text { (temperature }\right)+s_{3}(\text { salinity })+ \\
& s_{4}(\text { dissolved oxygen }) \times \varepsilon_{i}
\end{aligned}
$$

This model includes an intercept $(a)$, the coefficient $\left(b_{1}\right)$ for the Site term, which was specified as a factor, smoothers $\left(s_{n}\right)$ on all other predictor variables, and the error term $(\varepsilon)$, which is assumed to be independent and identically distributed (Zuur et al. 2009). Collinearity among the predictors was assessed with coplots and by plotting Pearson residuals (Zuur 2013), and best models were checked for overdispersion. Generalized cross-validation (GCV), a leave-one-out procedure designed to measure error, provided an additional evaluation of model fit and validity (Ciannelli et al. 2008) and is integrated within the 'gam' function in 'mgcv' package in R (R Development Core Team 2013). We used AIC for model selection and present model forms, AIC scores, GCV scores, and the amount of deviance explained (analogous to $\mathrm{r}^{2}$ ) for the models. We collected fitted values for the simulation period and retransformed the logged prediction values using a bias correction for lognormal distributions. These values were used as estimates of abundance for each DOY

\section{Estimation of silver perch production}

To estimate seasonal production, we used the bioenergetics model output for individual fish biomass ( $g$ in wet weight) in conjunction with estimates of abundance (density; no. fish $\mathrm{m}^{-2}$ ) for each simulation day. The product of these 2 values is the estimated biomass $\left(\mathrm{g} \mathrm{m}^{-2}\right)$ of the local population. As with the bioenergetics modeling, 15 June $(\mathrm{DOY}=166)$ to 15 October $(\mathrm{DOY}=288$ ) was the period of interest for estimating abundance, which corresponded to the time period of silver perch recruitment to the seagrass habitat and their subsequent growth.

We used the general equation $B_{t}=\left(\operatorname{catch}_{t} \times A\right) / e$, where biomass $(B)$ at time $t$ is equal to catch at time $t$ multiplied by the total area $(A)$ divided by the gear efficiency (e). Catch was defined as the number of fish per area swept per day (density) multiplied by the estimated biomass of an individual fish on the same day from the bioenergetics model, with resulting units of $\mathrm{g} \mathrm{m}^{-2}$. Initially, efficiency was assumed to be 1, which likely represents a significant underestimate given known gear inefficiencies (Rozas \& Minello 1997), but resulting values are comparable to other studies, many of which have not explicitly accounted for gear inefficiencies or may have used different gear types (e.g. Rooker et al. 1998). Additional calculations assumed gear efficiency to be 0.25 based upon the work of Kjelson \& Johnson (1978), which improves the realism of our density estimates for our gear type, habitat, and species.

Additionally, instantaneous mortality was estimated using catch curve analysis (Chapman \& Robson 1960, Simpfendorfer et al. 2005). Daily means of catch data (counts) were log transformed and the fully recruited age was determined. We then estimated the slope of the descending limb of the curve using linear regression. This approach is considered longitudinal catch curve analysis, where a cohort is followed across the growing season rather than across years, as is customary. In this analysis, the slope coefficient for the linear regression is equal to $Z$, instantaneous mortality. Since YOY silver perch are not subjected to fishing mortality, we assumed $Z=M$, where $M$ is natural mortality. This analysis assumes constant mortality across the time period, and a closed population - both of which may be violated, so our results represent a rough estimate of daily instantaneous mortality for YOY silver perch.

\section{RESULTS}

\section{Bioenergetics model}

Once constructed, the base bioenergetics model ( $p=0.5$ and all other parameter values as listed in Table 1) produced individual fish growth of approximately $5 \mathrm{~g}$ over the growing season, with a start weight of $0.1 \mathrm{~g}$ and an ending weight of just over $5.0 \mathrm{~g}$ (Fig. 2). Specific growth rate $\left(\mathrm{g} \mathrm{g}^{-1} \mathrm{~d}^{-1}\right)$ was variable, especially during shifts in prey base (associated with variable diet inputs based on weight, as in Table 1), but generally declined with fish growth (Fig. 2, second axis). Specific growth averaged 3\% body weight $\mathrm{d}^{-1}$ over the simulation period (min. $=0$, max. $=8 \%$ ). The gross conversion efficiency (change in biomass [g] / consumption, [g]) was 0.21. Consumption ranged from 10 to $26 \%$ body weight $\mathrm{d}^{-1}$, with a mean of $15 \%$ body weight $\mathrm{d}^{-1}$; smaller fish ate a higher ration. As temperatures were within the optimal range for consumption during the model period, the temperature dependence function for consumption ranged between 0.8 and 1.0 with a mean of 0.96 . As such, $C$ (i.e. consumption) was most influenced by $p$, rather than fluctuations in consumption based upon temperature. 


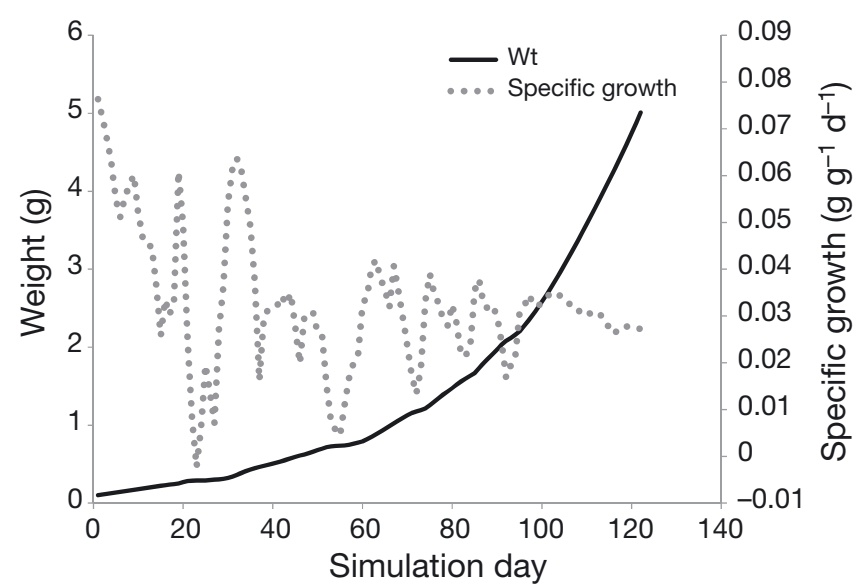

Fig. 2. Base silver perch bioenergetics model growth over the model simulation period. Solid black curve shows growth; dotted gray line shows specific growth. This output is for the base (uncalibrated) bioenergetics model, with parameter values as per Table 1 and $p=0.5$

Losses (respiration, digestion, egestion, and excretion) accounted for about $75 \%$ of daily consumption, with fish becoming more efficient with size. Respiration (excluding $S D A$ ) was the largest loss component and accounted for about half of the total daily loss, followed by $S D A$, egestion, and excretion, in descending order. Brett (1979) noted that nonrespiratory losses (digestion, excretion, and egestion) totaled 35 to $40 \%$ for carnivorous fishes; our average value of $32 \%$ is slightly below this benchmark, but still reasonable.

The model output was highly sensitive to the value of $p$, although when random stochasticity was added, the model was resilient to perturbation and growth was similar to the base model run. When $p$ was held constant, values less than 0.24 resulted in model failure (negative growth). Additionally, field observations indicated that the bioenergetics modelpredicted growth of $5 \mathrm{~g}$ was low relative to the size of fish we collected late in the season (which were over $15 \mathrm{~g}$ ). Adjusting $p$ to 0.6 generated output that more closely resembled field observations.

\section{Field data and bioenergetics model calibration}

Field data

During the summer of 2010, we collected over 2300 silver perch from 187 trawls. Length measurements were taken on 1900 fish, and length-weight measurements were recorded for 267 individuals. The length-weight regression for all biomass conversions (TL and wet weight) was:

$$
W=0.0000135 \times L^{2.99}
$$

with sizes ranging from 22 to $132 \mathrm{~mm}$ TL. Peak abundance occurred around 7 July (DOY $=188$ ), with a mean of 120 ind. tow ${ }^{-1}$ (averaged across all tows on that date), or 0.9 ind. $\mathrm{m}^{-2}$, and remained at high abundances for approximately $2 \mathrm{wk}$. This catch was comprised almost entirely of newly recruited YOY fish ( 30 mm TL), and subsequent sampling events showed declining abundances of YOY fish.

For the field-based weight-over-time growth models, the Gompertz model was the best fitting model (Table 2). While the model generally fitted the data well during the earlier dates, there was more variation in the residuals and deviance from the fitted model at the later dates (Fig. 3). This pattern is not unexpected, given variable growth rates among individuals and the difficulty distinguishing a strictly defined cohort in later time periods. Also, observed growth did not appear to reach a plateau (Fig. 3), and as such, there was higher uncertainty in the estimated asymptote of the Gompertz function.

\section{Model calibration}

We used the estimated growth from the Gompertz model to fit the base bioenergetics model by adjusting consumption via the $p$ term. The unconstrained optimization resulted in several values $>1$, but most were between 0.5 and 0.8 , suggesting that the bioen-

Table 2. Model output for field-based growth estimates of silver perch for overall models. Models were fit to weight data for a cohort in lower Chesapeake Bay by day of the year. Model selection was made by Akaike's information criterion (AIC), with the Gompertz model having the best fit

\begin{tabular}{|c|c|c|c|c|c|c|c|}
\hline \multirow[t]{2}{*}{ Model } & \multirow[t]{2}{*}{ AIC } & \multicolumn{3}{|c|}{ Parameter values/coefficients } & \multicolumn{2}{|c|}{ Standard error } & - \\
\hline & & Intercept & Slope & & Intercept & Slope & \\
\hline Linear & & & & & & & \\
\hline Weight Date & 5150 & -24.427 & 0.137 & & -25.23 & 29.7 & \\
\hline Exponential & & a & $b$ & & a & $b$ & \\
\hline Weight $\sim a \times \exp ($ Date $\times b)$ & 5147 & 0.983 & 0.031 & & 0.072 & 0.001 & \\
\hline Gompertz & & $a$ & $b$ & C & a & $b$ & C \\
\hline Weight $\sim a \times \exp [b \times \exp ($ Date $\times c)]$ & 5115 & 46.073 & -4.99 & -0.016 & 18.632 & 0.269 & 0.003 \\
\hline
\end{tabular}




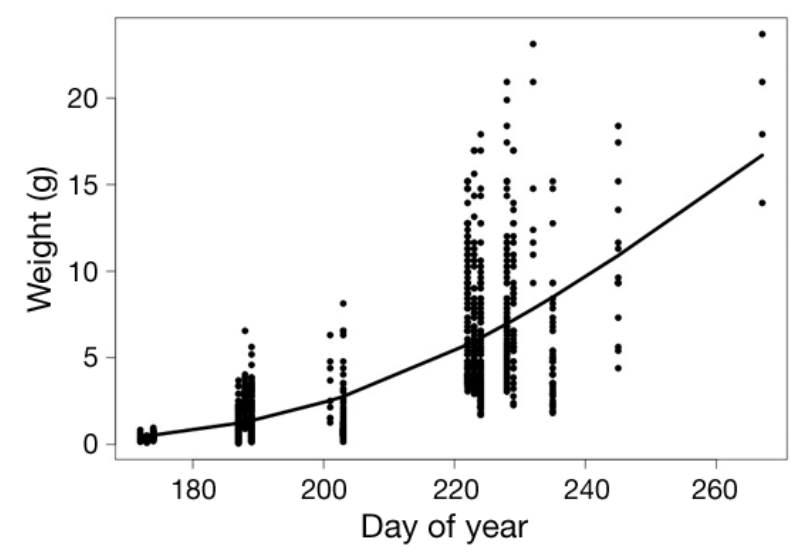

Fig. 3. Gompertz growth model for silver perch from Chesapeake Bay field-observed growth data. See Table 2 for model equation

ergetics model fit the growth model from field observations fairly well, with adjustments to $p$. When the $p$ term was constrained $(0<p<1)$ in the optimization, the values ranged from 0.43 to 0.82 , with a mean of 0.65 and standard deviation of 0.13 (Fig. 4). Total growth was $23.2 \mathrm{~g}$ over the $122 \mathrm{~d}$ model period, which results in daily instantaneous growth $(G)$ equal to 0.05 over the model period.

For the calibrated bioenergetics model, we evaluated output relating to growth, consumption, and losses (Table 3). Mean consumption was $14.5 \%$ body weight $\mathrm{d}^{-1}$ and a range of 6 to $38 \%$ (0.04 to $1.5 \mathrm{~g}$ ). The smaller fish ate the greatest proportion of their body

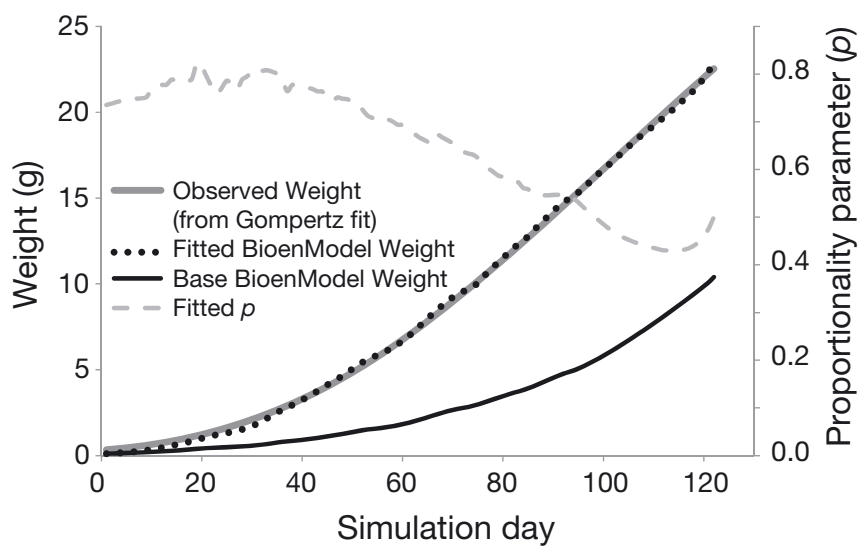

Fig. 4. Silver perch bioenergetics model fitted to Chesapeake Bay field data. Black solid line: base bioenergetics model output, where $p=0.5$. Gray solid line: observed individual fish weight from Gompertz growth model fitted to field data. Dotted black line: bioenergetics model output once fitted to the observed curve (calibrated model). Dashed light gray line: the proportionality parameter $(p)$ as it varied through time (second $y$-axis); the mean value of $p$ for the calibrated model was 0.65 weight, with values eventually dropping to $6 \%$ towards the end of the simulation period. While consumption of $38 \%$ of body weight seems high, the overall range and pattern fit with that reported previously in a laboratory setting (Brooks 1985) and with theory (Brett 1979). It is possible that the prey energy density of $2900 \mathrm{~J} \mathrm{~g}^{-1}$ for the smaller fish (eating copepods) is low, resulting in very high consumption rates needed to achieve the fitted growth. Total consumption over the $122 \mathrm{~d}$ growing period was $92.5 \mathrm{~g}$. The gross conversion efficiency (growth per gram of consumption) ranged from 0.14 to 0.50 , with a mean of 0.28 . Conversion efficiency declined as the fish grew. The mean value is high compared to those reported for other YOY fish (Hartman \& Brandt 1995b), but our estimates only represent the growing season and would be reduced by annualized calculations.

Related to consumption, we explored the sensitivity of the calibrated model to prey energy density, given diverse diets. A diet of prey with a constant energy density of $2900 \mathrm{~J} \mathrm{~g}^{-1}$ resulted in poor growth, less than $1.5 \mathrm{~g}$ across the simulation period, while a diet of prey with $3500 \mathrm{~J} \mathrm{~g}^{-1}$ resulted in growth of $7.2 \mathrm{~g}$, and a diet of $4500 \mathrm{~J} \mathrm{~g}^{-1}$ achieved growth of $19.7 \mathrm{~g}$. For comparison, varying the prey energy density as a function of weight (with fish consuming more energy-dense prey as they grow following our diet analysis) resulted in the observed base growth rate of approximately $0.19 \mathrm{~g} \mathrm{~d}^{-1}$, or $23.2 \mathrm{~g}$ over the model period. Incorporating variable prey energy densities based on actual diets improved the realism of the model.

Losses accounted for an average of $67 \%$ of consumption, with a maximum value of $79 \%$ and minimum value of $54 \%$. Respiration accounted for more than half of the loss term over the simulation period, although values were variable by day, ranging from 41 to $59 \%$. Unlike the consumption terms, which varied with fish size, losses tended to be relatively stable across the range of growth. Losses attributable to digestion, excretion, and egestion were approximately $32 \%$, as in the base model.

\section{Sensitivity analyses}

The individual parameter perturbation showed $R Q$ and $C A$ to be the most sensitive parameters, although rank order varied by level of disturbance, with $R Q$ being most sensitive at 2 and $20 \% C V$, and $C A$ most prone to prediction error at $10 \%$. $R B$ was the least sensitive parameter of those analyzed, with $C B$ also seemingly stable when perturbed. $R A$ was 
Table 3. Comparison of the base, calibrated, and temperature-manipulated silver perch bioenergetics models. Mean values are averages across the $122 \mathrm{~d}$ simulation period; ranges are the minimum and maximum during the same period. $C=C$ Consumption; $R=$ respiration; $F=$ egestion; $U=$ excretion; $p=$ proportion of maximum consumption; $S=$ coefficient for specific dynamic action; $G$ = growth; $G C E=$ Growth conversion efficiency

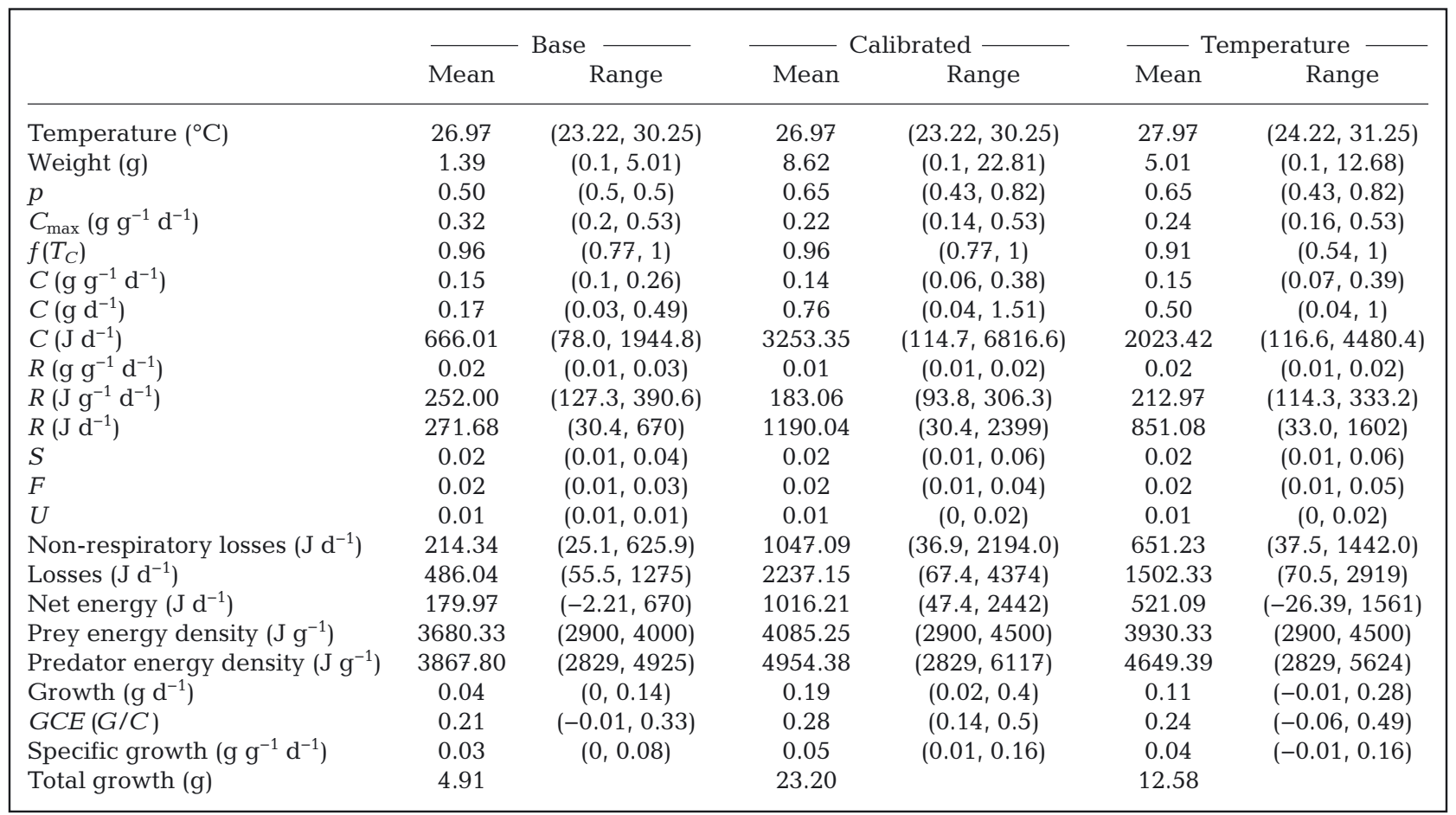

intermediate among the group. During model development, we found $R Q$ to be particularly sensitive, probably due to the exponential nature of the relationship for respiration.

Perturbations of the $p$ parameter produced little change in overall growth when error with 2 and $10 \%$ CV was added (naïve 95\% confidence intervals for $2 \%=22.4-24.2 \mathrm{~g}$, for $10 \%=21.2-25.4 \mathrm{~g}$; calibrated model growth was $23.2 \mathrm{~g}$ for reference). When error of $20 \% \mathrm{CV}$ was added, the range of growth values increased, with a confidence interval of 19.0-27.8 $\mathrm{g}$. These values are reasonable given field observations and represent less than a $20 \%$ change from the calibrated growth of $23.2 \mathrm{~g}$, suggesting that error is not magnified by the growth model. So, while the model is sensitive to input values for $p$, even with considerable variation in feeding proportions, the model produces reasonable growth. Given that ecological conditions can be highly variable in time and space and the true value of $p$ is unknown, we used the results from the $20 \%$ CV simulations to inform our calculations of potential production (see 'Production estimates').

The temperature perturbation showed that a $1^{\circ}$ increase in water temperature can have a consider- able impact on fish growth. The modeled silver perch grew $12 \mathrm{~g}$ during the simulation period when water temperatures were increased by $1{ }^{\circ} \mathrm{C}$. This result is approximately $55 \%$ of the growth achieved using the 2010 temperatures in the calibrated model. Because we did not vary input of any other parameters (and used the optimized values of $p$ averaging 0.65 ), this reduction in growth is directly tied to increased metabolic demands, as realized through the temperature dependence components of the consumption and respiration equations (Eqs. 2 \& 9). The summarized means and ranges for all model components are compared to the base model and the calibrated model in Table 3. If we assume the calibrated model is an ideal growth model for silver perch under field conditions, a fish would have to consume an additional $10 \% \mathrm{~d}^{-1}$ to obtain similar growth to that observed under the 2010 temperature scenario.

\section{Abundance estimates}

GAM was an appropriate approach for modeling silver perch abundance, given the overall domeshape in the response. The non-parametric smoothers 
Table 4. Model output from silver perch abundance estimates $\left(\mathrm{NM} 2=\mathrm{no} . \mathrm{m}^{-2}\right.$ ) using generalized additive models $(\mathrm{GAMs})$. The best model, using Akaike's information criterion (AIC) scores, was the model with day of the year (DOY) and dissolved oxygen (DO). Deviance explained is similar to $\mathrm{r}^{2}$ and GCV score is the value of the generalized cross validation procedure, which is a leave-one-out fitting method for assessing model fit

\begin{tabular}{|c|c|c|c|c|}
\hline Model & Form & Deviance explained (\%) & AIC & GCV Score \\
\hline GAM.1 & $\log . \mathrm{NM} 2 \sim s(\mathrm{DOY})+$ factor $($ Site $)+s(\mathrm{Temp})+s(\mathrm{Sal})+s(\mathrm{DO})$ & 74.0 & 557.0 & 1.15 \\
\hline GAM.2 & log.NM2 $\sim s(\mathrm{DOY})+s(\mathrm{Temp})+s(\mathrm{Sal})+s(\mathrm{DO})$ & 73.9 & 556.2 & 1.16 \\
\hline GAM.3 & log.NM2 $\sim s(\mathrm{DOY})+s(\mathrm{Temp})+s(\mathrm{DO})$ & 73.0 & 555.4 & 1.14 \\
\hline GAM.4 & log.NM2 $\sim s(\mathrm{DOY})+s(\mathrm{DO})$ & 72.9 & 554.2 & 1.13 \\
\hline GAM.5 & $\log . \mathrm{NM} 2 \sim s(\mathrm{DOY})$ & 68.9 & 567.0 & 1.20 \\
\hline
\end{tabular}

allowed for good model fit with high explained deviance (over $65 \%$ for all models), low GCV scores, and low residual variance. We compared 5 candidate models using AIC, and the best fitting model included the smoothed date and dissolved oxygen terms (Table 4). This model explained $73 \%$ of the variation in the data and the resulting fit represents the overall pattern in abundance, with a peak in the middle of the dataset (early July) followed by a decline (Fig. 5). All models were similar in AIC scores; when terms were dropped in sequence from the full model, fit improved marginally. Site was the least significant factor in the full model. DOY was the most influential predictor, with the shape of the smoothed fit very similar to the full model. While overall the model fit the data well, peak abundance was not fully captured, so our predicted abundances are likely underestimates.

\section{Production estimates}

Estimated biomass followed the same general form as the abundance estimates (Fig. 6). Peak biomass occurred after peak abundance, taking into account

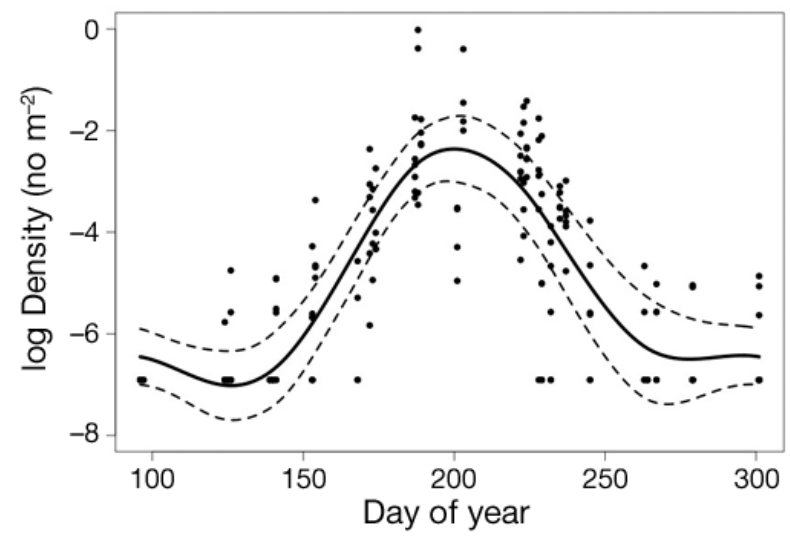

Fig. 5. Estimate of silver perch abundance in lower Chesapeake Bay from generalized additive model (GAM). Note model and standard error (dashed lines)are fitted to logged values of density the growth of individuals and the high numbers of fish during this time period. Using the confidence interval from the error analysis, peak biomass occurred around DOY 215 (the first week of August) and was estimated to be $0.56 \mathrm{~g} \mathrm{~m}^{-2}$, with a range of 0.47 to $0.76 \mathrm{~g} \mathrm{~m}^{-2}$ (Fig. 6). The total production of one cohort of silver perch from a growing season was estimated to be $22.9 \mathrm{~g} \mathrm{~m}^{-2}$, with a range of 19.5 to $29.5 \mathrm{~g} \mathrm{~m}^{-2}$, when $e=1$. When gear efficiency was considered $(e=0.25)$, production was $91.5 \mathrm{~g} \mathrm{~m}^{-2}$ (range of 77.8 to $117.8 \mathrm{~g} \mathrm{~m}^{-2}$ ) for the single cohort followed through time.

Using the catch curve analysis, $Z$ during the model period was estimated to be 0.054 for YOY silver perch, with lower and upper confidence limits of 0.03 and 0.08. This value reflects mortality of fish expressly in seagrass habitats, where main predators

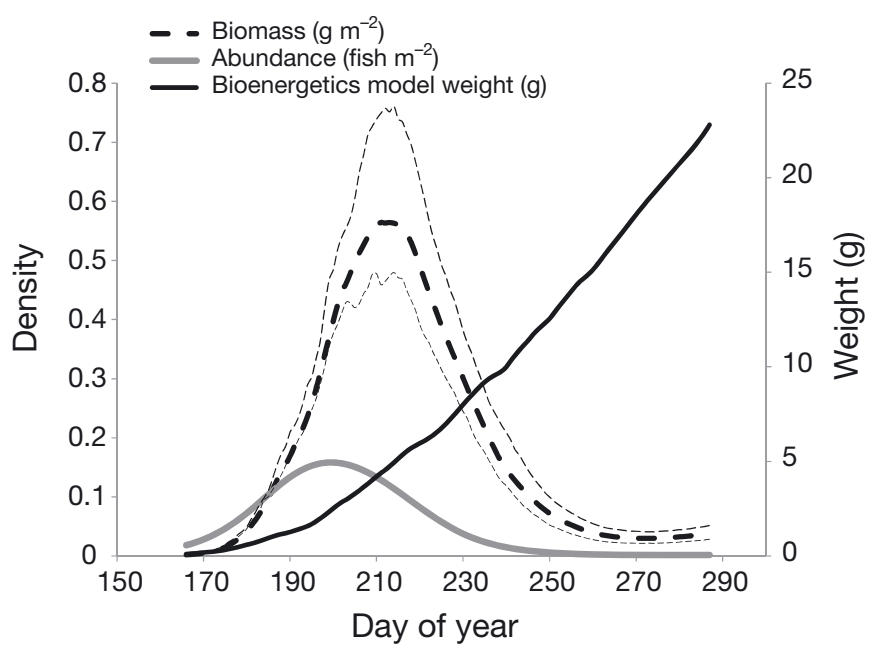

Fig. 6. Estimates of silver perch biomass using the growth estimate from the bioenergetics model (black line, second $y$ axis) and abundance estimate from generalized additive model (GAM) for density of fish (gray line, $y$-axis). The seasonal population biomass is shown as the thick dashed black line, peaking shortly after maximum abundance and declining towards the end of the summer season. Thin dashed lines: naïve $95 \%$ confidence intervals, with error of $20 \% \mathrm{CV}$ added to the growth model. Units for the estimated biomass curve are $\mathrm{g} \mathrm{m}^{-2}$ 
are likely to be birds and larger piscivores foraging on high tides. Given this high mortality, the overall rapid decline in biomass coincides with declining abundances, despite the increase in individual fish size during later time periods.

We estimated the area surveyed at the Goodwin Island site to be approximately $13.75 \mathrm{ha}$. We used this area as the total area surveyed multiplied by the catch $\left(\mathrm{g} \mathrm{m}^{-2}\right)$ to arrive at overall production of $12600 \mathrm{~kg}$ of silver perch in the 2010 growing season from one representative seagrass site (this value uses the total production based on $e=0.25$ ). Given about 8100 ha of seagrass in lower Chesapeake Bay in 2010 (Orth et al. 2013), the production of silver perch throughout the lower Bay was estimated to be $7415 \mathrm{t}$ (range $=6305$ to $9542 \mathrm{t}$ ) for 2010. For reference, the average commercial fishery landings of Atlantic croaker for Virginia over the last decade were approximately $5000 \mathrm{t} \mathrm{yr}^{-1}$ (ASMFC 2014).

\section{DISCUSSION}

The use of field-collected abundance data in combination with an individual-based bioenergetics model allowed us to model production of silver perch in a representative seagrass habitat in lower Chesapeake Bay. While the field data supported both abundance estimates and calibration of the growth model, the inclusion of the bioenergetics model in the analysis provided further confidence in defining growth in a species that is known to spawn repeatedly, resulting in collection of multiple cohorts in any given sample. While we confined our analyses to the growing season (summer months), our estimates of production could be considered annual estimates from this habitat type, as fish migrate out of these habitats in early fall.

\section{Bioenergetics model}

Our bioenergetics model expressed realistic silver perch growth relative to our field data and resulted in rates for each model sub-equation that were comparable to those observed for similar species in this region. The minimal changes to the proportionality constant required for the base model to agree with the field-generated growth rate was indicative of robust model parameter starting values. Model development in conjunction with field data afforded higher confidence in growth estimates.

Previous analyses have indicated that functions describing the effect of body mass and temperature on maximum consumption and respiration contain the most sensitive parameters in the bioenergetics model (Bartell et al. 1986). While the available lab data did not measure consumption or respiration at the full range of temperatures experienced by fish during our field study, using available data on lethal limits (Pattillo et al. 1997), respiration rates for other species (Wuenschel et al. 2004, Horodysky et al. 2011), and other bioenergetics analyses (Hartman \& Brandt 1995a,b, Stevens et al. 2006, Nye 2008), the parameter values we used appeared sufficient to produce realistic growth. By using the metabolic rates from lab studies on silver perch (Brooks 1985) and comparing them to more recent lab data from sympatric sciaenid species (Horodysky et al. 2011), the values used in the model gave expected estimations for loss due to respiration. The resting metabolism of silver perch as measured by Brooks (1985) is intermediate between that of spot and Atlantic croaker (Horodysky et al. 2011). Spot and Atlantic croaker metabolisms were similar to those of other sciaenids, with the exception of Menticirrhus spp. (Horodysky et al. 2011), and as such, it appears silver perch has a metabolic rate characteristic of other Chesapeake Bay sciaenids.

In addition to the model parameters evaluated through the sensitivity analysis, exploratory analyses related to model development revealed prey energy densities to be influential to the modeled growth. In fishes with diverse and changing diets, such as juvenile silver perch, prey energy density values can have an effect on estimated growth, especially where diets change with habitat or ontogeny. More realistic model fit (when compared to field data) was observed when prey energy densities were based upon actual diets than when a general value (e.g. constant $4000 \mathrm{~J} \mathrm{~g}^{-1}$ ) was used. Bartell et al. (1986) found that variations in diet input were not influential in model performance. However, that study did not specifically evaluate juvenile fishes, where diets change with ontogeny. Other modelers have shown large differences in many model parameters between juvenile and adult fishes (Kitchell et al. 1977, Hartman \& Brandt 1995a, Koehler et al. 2006, Wuenschel et al. 2006), and adjusting prey energy densities to account for changing diets seems necessary to produce realistic growth in rapidly growing fishes.

Among the sizes of silver perch we collected in the field, the dominant prey item was mysid shrimp. We found reported energy density values for mysids to range from 2927 to $4868 \mathrm{~J} \mathrm{~g}^{-1}$ (Cummins \& Wuycheck 1971, Lasenby 1971, Hanson et al. 1997, J. McIntyre unpubl. data). We used a value of $4000 \mathrm{~J} \mathrm{~g}^{-1}$ for prey 
energy density for 40 to $90 \mathrm{~mm}$ fish, which primarily ate mysid shrimp. The main species found in silver perch diets was Americamysis bigelowi, a mysid found in shallow vegetated habitats, with Neomysis americana, a more broadly distributed mysid in Chesapeake Bay, also common; energy densities for these 2 species were not found in the literature. We also found that fish in our study preferentially consumed mysids until a larger size than previously reported (Chao \& Musick 1977, Waggy et al. 2007). Lankford \& Targett (1997) showed that mysids were a preferred prey for weakfish due to their postconsumptive handling efficiency, which may be one reason why they are a preferred prey of silver perch, especially during periods of high fish abundance, where density-dependent prey limitation of larger crustaceans (e.g. sand shrimp Crangon septempinosa) could be occurring. The time of occupancy of silver perch in seagrass beds coincides with a period of high production, but very little abundance or density data exist for mysids in these habitats. Given the prevalence of mysids in the diet over the growing season, understanding the population dynamics of this group would be useful for better understanding trophodynamics of silver perch, as well as many other YOY Chesapeake Bay fishes.

Other studies of juvenile sciaenid rearing have shown that estuarine growth rates were dependent upon environmental conditions, such as water temperature and time of settlement (Lankford \& Targett 1994, Lanier \& Scharf 2007). In fact, water temperature has been cited as the single most important factor controlling fish growth (Fry 1971). With the availability of daily temperature data in close proximity to our field sites, and the collection of water quality data coincident with fish collection, we had high confidence in the thermal regime experienced by the fishes in this study. Because both the consumption and respiration terms are temperature dependent, having an accurate picture of thermal regime improved our ability to accurately estimate growth. Additionally, the temperatures experienced by fish in our study were within a small range of temperatures generally preferred by silver perch. Even so, our application of the bioenergetics model for the temperature manipulation/sensitivity analysis illustrated the effect that a $1{ }^{\circ} \mathrm{C}$ temperature change can have, even within the preferred temperature range. While a consistent increase in temperature is likely to affect the entire food web, it is worth understanding the impacts to individual species, especially when they occur in high abundance during discrete time periods, as silver perch does.

\section{Growth and consumption}

Reported growth rates for YOY silver perch are variable. Killam et al. (1992) reported growth rates of 7 to $22 \mathrm{~mm} \mathrm{mo}^{-1}$ from Tampa Bay; other estimates from the Atlantic Ocean were slightly higher at 10 to $30 \mathrm{~mm} \mathrm{mo}^{-1}$ (de Sylva et al. 1962, Chao \& Musick 1977). With estimated growth of $23.2 \mathrm{~g}$ over the $122 \mathrm{~d}$ simulation period, the mean growth rate in this study was approximately $0.19 \mathrm{~g} \mathrm{~d}^{-1}\left(5.7 \mathrm{~g} \mathrm{mo}^{-1}\right)$, which equates to $0.9 \mathrm{~mm} \mathrm{~d}^{-1}$ or $27 \mathrm{~mm} \mathrm{mo}^{-1}$. This value is at the high end of reported values, although similar to what Chao \& Musick (1977) found based on histograms, for the same region. Daily growth rates for spot in North Carolina tidal marshes were reported to be approximately $0.03 \mathrm{~g} \mathrm{~g}^{-1} \mathrm{~d}^{-1}$ (Currin et al. 1984 and references therein); this is slightly lower than our estimate for silver perch, which was $0.05 \mathrm{~g} \mathrm{~g}^{-1} \mathrm{~d}^{-1}$ (averaged over model period). This higher growth could be attributable to more favorable estuarine rearing conditions during our study or improved growth estimates resulting from the combination of field observations and the bioenergetics model. While our field-based estimate of growth was imprecise due to the potential for sequential spawning and variance associated with individual growth rates as time progressed (Fuiman et al. 2005), the fitted bioenergetics model did seem to estimate realistic and comparable growth rates for this species.

Overall, the estimated consumption of $93 \mathrm{~g}$ over the $122 \mathrm{~d}$ simulation period is similar to what was estimated for other YOY fish in Chesapeake Bay. Hartman \& Brandt (1995b) estimated that an individual YOY striped bass consumed $142 \mathrm{~g}$ of prey annually, while a YOY weakfish consumed $54 \mathrm{~g}$ to $296 \mathrm{~g}$ in a year. Our value of $93 \mathrm{~g}$ fits with these other values, especially since it represents the season of maximum consumption for a species with a much smaller maximum size than either striped bass or weakfish. A decrease in water temperature associated with movement to deeper habitats would lower metabolism and reduce caloric demand for the fish.

\section{Abundance and production}

While fitting statistical models to the size data resulted in several forms with reasonably good fits, only GAM approaches adequately captured the relationships in the abundance data. During model exploration, we fit generalized linear models to the data, but these models could not account for the declining trend towards the latter part of the season. 
The addition of the non-parametric smoother for the DOY factor helped achieve a good model fit with a high degree of explained error. It was somewhat surprising that dissolved oxygen contributed to explained error in the best model. In early exploratory data analyses, coplots and biplots of this factor and the response variable did not show any obvious relationship. However, the smoothed function showed a dip in abundance below $5 \mathrm{mg} \mathrm{l}^{-1}$. This factor contributed to explaining variance in the response, as evidenced by the increased AIC score with date alone. While low dissolved oxygen was not commonly observed in seagrass habitats during this study, we note that silver perch abundances appeared to be lower with reduced dissolved oxygen. This response has been shown for many species (Kramer 1987, Breitburg 1994).

Estimates of abundance showed a peak during early July, with decreasing numbers thereafter, most likely due to high predation mortality but also possibly due to emigration. While 2 sites (Goodwin Island and Pepper Creek) had very high abundances during early July, the Browns Bay site did not. The bi-weekly sampling may not have captured peak recruitment at this site, or perhaps habitat quality was not as high, and thus fewer silver perch used that area for rearing. The densities we observed at peak recruitment were similar to those observed in other systems. During peak settlement in a Texas seagrass meadow, mean densities of silver perch ranged from 0.04 to 2.6 fish $\mathrm{m}^{-2}$, depending upon habitat type (Rooker et al. 1998). Although the seagrass species (Halodule wrightii, Thalassia testudinum) were different than those in lower Chesapeake Bay, this study provides a reference of approximate density. Our model-estimated value of 0.2 fish $\mathrm{m}^{-2}$ and raw data value of 0.9 fish $\mathrm{m}^{-2}$ both fall within the range observed by Rooker et al. (1998). Additional sampling during periods of peak abundance may have aided in determining whether the high abundances we observed were widespread and persistent or if our samples were taken through a locally dense patch.

Along with the likely underestimate produced by the GAM, our overall biomass estimate is also quite likely an underestimate even when accounting for gear inefficiencies. As with other trawl surveys, it is probable that our sample was not representative of the actual available biomass due to sampling error, net evasion, etc., and with the absence of survey-specific efficiency estimates, the applied efficiency of 0.25 from Kjelson \& Johnson (1978) is our best estimate. Our study sites were very shallow (on the order of 1.5 to $2.0 \mathrm{~m}$ at high tide) and the otter trawl used likely captured much of the water column at the time of sampling. While many gear types for collecting nekton have been shown to be problematic in vegetation (Rozas \& Minello 1997), with the correction for gear inefficiency, our estimates were improved. The bottom trawl is commonly used and is a logistically efficient means for collection, although our abundance and overall production estimates should be viewed as minimums given known inefficiencies for this gear type.

To our knowledge, mortality rates have not been reported from this region for silver perch. Our daily instantaneous rate of 0.05 (range of 0.03 to 0.08 ) is high even for YOY fishes, which are known to have very high mortality (M. Smith \& J. Hoenig pers. comm.). However, the mortality rates for juvenile spot and Atlantic croaker in tidal marshes were estimated as 0.03 and $0.02 \mathrm{~d}^{-1}$, respectively (Weinstein \& Walters 1981, Currin et al. 1984), so our findings are similar. Currin et al. (1984) attributed mortality mainly to predation, with cold winter temperatures as an additional source of loss. Improved estimates of YOY mortality would enhance our production model. At the outset of this study, we aimed to measure survival (and growth) of silver perch using a markrecapture study. We attempted mark-recapture studies in 2010 and 2011, but did not recapture a significant number of fish in either year to utilize the proposed statistical models for estimating survival. Unlike tidal channel systems, our seagrass study site was open, perhaps allowing the fish to more readily emigrate. In addition, the summer of 2010 was very warm, with water temperatures above $30^{\circ} \mathrm{C}$ on consecutive days. While eelgrass typically dies back in the summer before resuming growth in the fall, during this year there was a large-scale die-off of plants in July, leading to reduced structural habitat (R. J. Orth \& K. L. Sobocinski pers. obs.). This coincided with a drastic reduction in silver perch abundance, which likely included many of the animals that were tagged.

Production from various habitat types is of interest to natural resource and fisheries managers tasked with conservation and management (NMFS 2010). Our overall production estimate of $22.9 \mathrm{~g} \mathrm{~m}^{-2}$ (when $e=1$ ) compares favorably with estimates of spot production from a North Carolina tidal marsh of 0.25 to $7.5 \mathrm{~g} \mathrm{~m}^{-2}$ (Currin et al. 1984). Although the silver perch production estimate presented here is higher, spot are known to make use of more habitat types as juveniles (Orth \& Heck 1980, Heck \& Thoman 1984, Rooker et al. 1998), potentially lessening the contribution from any one habitat. 
Although we urge caution when interpreting the overall lower Chesapeake Bay production estimates of $7415 \mathrm{t}$, as differences in production between eastern and western shores of the Bay have been observed for other species (Smith et al. 2008), this value is quite likely an underestimate as it represents production of only 1 cohort-albeit the largest cohort we observed in our field collections - through time. As sequential spawners, it is likely that the actual production of silver perch is 5- to 10 -fold higher, based on our field observations of the duration of recruits in the system (from June through mid August). The values presented here express the potential biomass transfer of this known seagrass-rearing species which, as we have shown, is substantial. The maximum size of an individual adult silver perch in Chesapeake Bay is approximately $30 \mathrm{~cm}$ (Murdy et al. 1997); thus, this species holds little commercial or recreational interest except as bait. However, given its considerable production and standing stock biomass during mid- to late-summer in lower Chesapeake Bay, it represents an important trophic link between primary consumers and piscivores. Additionally, strong habitat affinity to seagrass beds during the juvenile stage provides a direct link between these shallow-water systems and deeper Bay waters.

\section{CONCLUSIONS}

The bioenergetics model combined with field data resulted in a thorough picture of silver perch growth, abundance, and production in lower Chesapeake Bay seagrass beds. While only one species, this study provides a comprehensive overview of the value of seagrass habitats to a common and seasonally abundant fish in this region. Because this species exhibits seasonal migrations to other habitats (deeper waters within Chesapeake Bay and offshore), the silver perch biomass produced in seagrass habitats is exported, contributing to production of higher trophic levels via trophic transfer in the near-coastal region, and acting as an energetic subsidy from seagrass habitats.

Acknowledgements. A considerable field effort was at the heart of this study and we thank many volunteers and staff, including Jacques van Montfrans, Ryan Norris, Carissa Gervasi, Nico Hernandez, and many VIMS graduate students. Andre Buchheister, Amy Then, Mark Nelson, and Ken Heck provided helpful insight on analytical methods and approach. We appreciate the GIS assistance provided by David Wilcox and Jennifer Burke and thank 3 anonymous reviewers for additional comments that improved the manuscript. Funding was provided in part by the Virginia Marine
Resources Commission Recreational Fishing Advisory Board and the VIMS Hunter B. Andrews, Jr. Fellowship to K.L.S. This paper is Contribution No. 3410 of the Virginia Institute of Marine Science, College of William \& Mary.

\section{LITERATURE CITED}

Adams SM (1976) Feeding ecology of eelgrass fish communities. Trans Am Fish Soc 105:514-519

Allen MC, Read AJ, Gaudet J, Sayigh LS (2001) Fine-scale habitat selection of foraging bottlenose dolphins Tursiops truncatus near Clearwater, Florida. Mar Ecol Prog Ser 222:253-264

ASMFC (Atlantic States Marine Fisheries Commission) (2014) Atlantic croaker. www.asmfc.org/species/atlanticcroaker (accessed 20 Feb 2014)

Ayala-Pérez LA, Ramos-Miranda J, Tapia-García M, Salgado-Ugarte IH, Miranda G (2006) Distribution, abundance and population parameters of the silver perch Bairdiella chrysoura (Lacépède, 1802) (Pisces: Sciaenidae) in Terminos Lagoon, Campeche, Mexico. Thalassas 22:9-18

Barbier EB, Hacker SD, Kennedy CJ, Koch EW, Stier AC, Silliman BR (2011) The value of estuarine and coastal ecosystem services. Ecol Monogr 81:169-183

Bartell SM, Breck JE, Gardner RH, Brenkert AL (1986) Individual parameter perturbation and error analysis of fish bioenergetics models. Can J Fish Aquat Sci 43:160-168

$>$ Beck MW, Heck KL, Able KW, Childers DL and others (2001) The identification, conservation, and management of estuarine and marine nurseries for fish and invertebrates. Bioscience 51:633-641

Breitburg DL (1994) Behavioral response of fish larvae to low dissolved oxygen concentrations in a stratified water column. Mar Biol 120:615-625

Brett JR (1979) Environmental factors and growth. In: Hoar WS, Randall DJ, Brett JR (eds) Fish physiology, Vol. 8. Academic Press, London, p 599-675

Brooks HA (1985) Energy utilization model for Bairdiella chrysoura. PhD dissertation, The College of William and Mary, Williamsburg, VA

Burnham KP, Anderson DR (2002) Model selection and inference: a practical information-theoretical approach. Springer-Verlag, New York, NY

Chao LN, Musick JA (1977) Life history, feeding habits, and functional morphology of juvenile sciaenid fishes in the York River estuary, Virginia. Fish Bull 75:657-702

Chapman DG, Robson DS (1960) The analysis of a catch curve. Biometrics 16:354-368

Ciannelli L, Fauchald P, Chan KS, Agostini VN, Dingsør GE (2008) Spatial fisheries ecology: recent progress and future prospects. J Mar Syst 71:223-236

Costanza R, D'Arge R, De Groot R, Farber S and others (1997) The value of the world's ecosystem services and natural capital. Nature 387:253-260

Craig JK, Burke BJ, Crowder LB, Rice JA (2006) Prey growth and size-dependent predation in juvenile estuarine fishes: experimental and model analyses. Ecology 87: 2366-2377

Cummins KW, Wuycheck JC (1971) Caloric equivalents for investigations in ecological energetics. Mitt Int Ver Theor Angew Limnol 18

Currin BM, Reed JP, Miller JM (1984) Growth, production, food consumption, and mortality of juvenile spot and 
croaker: a comparison of tidal and nontidal nursery areas. Estuaries 7:451-459

de Sylva DP, Kalber FA, Shuster CN Jr (1962) Fishes and ecological conditions in the shore zone of the Delaware Estuary. Information Series No. 5, University of Delaware Marine Laboratories, Newark, DE

Elliott JM, Persson L (1978) The estimation of daily rates of food consumption for fish. J Anim Ecol 47:977-991

Ellis J, Musick J (2007) Ontogenetic changes in the diet of the sandbar shark, Carcharhinus plumbeus, in lower Chesapeake Bay and Virginia (USA) coastal waters. Environ Biol Fishes 80:51-67

> Fredette TJ, Diaz RJ, van Montfrans J, Orth RJ (1990) Secondary production within a seagrass bed (Zostera marina and Ruppia maritima) in lower Chesapeake Bay. Estuaries 13:431-440

Froeschke JT, Stunz GW (2012) Hierarchical and interactive habitat selection in response to abiotic and biotic factors: the effect of hypoxia on habitat selection of juvenile estuarine fishes. Environ Biol Fishes 93:31-41

Fry FEJ (1971) The effect of environmental factors on the physiology of fish. In: Hoar WS, Randall DJ (eds) Fish physiology, Vol 6. Academic Press, New York, NY, p 1-98

Fuiman LA, Cowan JH Jr, Smith ME, O'Neal JP (2005) Behavior and recruitment success in fish larvae: variation with growth rate and the batch effect. Can J Fish Aquat Sci 62:1337-1349

Gillanders BM (2006) Seagrasses, fish, and fisheries. In: Larkum AWD, Orth RJ, Duarte CM (eds) Seagrasses: biology, ecology, and conservation. Springer, Amsterdam, p 503-536

Grammer GL, Brown-Peterson NJ, Peterson MS, Comyns $\mathrm{BH}$ (2009) Life history of silver perch Bairdiella chrysoura (Lacépède, 1803) in north-central Gulf of Mexico estuaries. Gulf Mex Sci 1:62-73

Grol MGG, Rypel AL, Nagelkerken I (2014) Growth potential and predation risk drive ontogenetic shifts among nursery habitats in a coral reef fish. Mar Ecol Prog Ser 502:229-244

Hanson PC, Johnson TB, Schindler DE, Kitchell JF (1997) Fish bioenergetics 3.0. University of Wisconsin, Sea Grant Institute Technical Report No. WISCU-T-97-001, Madison, WI

- Hartman KJ, Brandt SB (1995a) Comparative energetics and the development of bioenergetics models for sympatric estuarine piscivores. Can J Fish Aquat Sci 52:1647-1666

> Hartman KJ, Brandt SB (1995b) Predatory demand and impact of striped bass, bluefish, and weakfish in the Chesapeake Bay: applications of bioenergetics modeling. Can J Fish Aquat Sci 52:1667-1687

Hartman KJ, Brandt SB (1995c) Estimating energy density of fish. Trans Am Fish Soc 124:347-355

Heck KL, Thoman TA (1984) The nursery role of seagrass meadows in the upper and lower reaches of the Chesapeake Bay. Estuaries 7:70-92

Heck KL Jr, Hays J, Orth RJ (2003) Critical evaluation of the nursery role hypothesis for seagrass meadows. Mar Ecol Prog Ser 253:123-136

Hewett SW, Johnson BL (1992) A generalized bioenergetics model of fish growth for microcomputers. University of Wisconsin Sea Grant Institute, Technical Report No. WIS-SG-92-250, Madison, WI

Horodysky AZ, Brill RW, Bushnell PG, Musick JA, Latour RJ (2011) Comparative metabolic rates of common western
North Atlantic sciaenid fishes. J Fish Biol 79:235-255

Houde ED (1987) Fish early life dynamics and recruitment variability. Am Fish Soc Symp 2:17-29

Houde ED (1989) Comparative growth, mortality, and energetics of marine fish larvae: temperature and implied latitudinal effects. Fish Bull 87:471-495

Jones CM (2014) Can we predict the future: juvenile finfish and their seagrass nurseries in the Chesapeake Bay. ICES J Mar Sci 71:681-688

Killam KA, Hochberg RJ, Rzemien EC (1992) Synthesis of basic life histories of Tampa Bay species. Tech Pub \#1092, Tampa Bay National Estuary Program, St. Petersburg, FL

Kitchell JF, Stewart DL, Weininger D (1977) Applications of a bioenergetics model to yellow perch (Perca flavescens) and walleye (Stizostedion vitreum vitreum). J Fish Res Board Can 34:1922-1935

Kjelson MA, Johnson GN (1978) Catch efficiencies of a 6.1-meter otter trawl for estuarine fish populations. Trans Am Fish Soc 107:246-254

Koehler ME, Fresh KL, Beauchamp DA, Cordell JR, Simenstad CA, Seiler DE (2006) Diet and bioenergetics of lakerearing juvenile Chinook salmon in Lake Washington. Trans Am Fish Soc 135:1580-1591

Kramer DL (1987) Dissolved oxygen and fish behavior. Environ Biol Fishes 18:81-92

> Lanier JM, Scharf FS (2007) Experimental investigation of spatial and temporal variation in estuarine growth of age-0 juvenile red drum (Sciaenops ocellatus). J Exp Mar Biol Ecol 349:131-141

> Lankford TE, Targett TE (1994) Suitability of estuarine nursery zones for juvenile weakfish (Cynoscion regalis): effects of temperature and salinity on feeding, growth and survival. Mar Biol 119:611-620

Lasenby DC (1971) The ecology of Mysis relicta in an arctic and a temperate lake. PhD thesis, University of Toronto

Laslett GM, Eveson JP, Polacheck T (2004) Fitting growth models to length frequency data. ICES J Mar Sci 61: 218-230

> Latour RJ, Brush MJ, Bonzek CF (2003) Toward ecosystembased fisheries management: strategies for multispecies modeling and associated data requirements. Fisheries 28:10-22

Liquete C, Piroddi C, Drakou EG, Gurney L and others (2013) Current status and future prospects for the assessment of marine and coastal ecosystem services: a systematic review. PLoS ONE 8:e67737

Luo J, Brandt SB (1993) Bay anchovy Anchoa mitchilli production and consumption in mid-Chesapeake Bay based on a bioenergetics model and acoustic measures of fish abundance. Mar Ecol Prog Ser 98:223-236

Madon SP, Williams GD, West JM, Zedler JB (2001) The importance of marsh access to growth of the California killifish, Fundulus parvipinnis, evaluated through bioenergetics modeling. Ecol Modell 136:149-165

> Mattila J, Chaplin G, Eilers MR, Heck KL, O'Neal JP, Valentine JF (1999) Spatial and diurnal distribution of invertebrate and fish fauna of a Zostera marina bed and nearby unvegetated sediments in Damariscotta River, Maine (USA). J Sea Res 41:321-332

> Moore KA, Jarvis JC (2008) Environmental factors affecting recent summertime eelgrass diebacks in the lower Chesapeake Bay: implications for long-term persistence. J Coast Res (Spec Issue) 55:135-147

Murdy EO, Birdsong RS, Musick JA (1997) Fishes of Chesa- 
peake Bay. Smithsonian Institution Press, Washington, DC

Najjar RG, Pyke CR, Adams MB, Breitburg D and others (2010) Potential climate-change impacts on the Chesapeake Bay. Estuar Coast Shelf Sci 86:1-20

NMFS (National Marine Fisheries Service) (2010) Habitat assessment improvement plan. Report of the National Marine Fisheries Service Habitat Assessment Improvement Plan Team. US Dept Comm, NOAA Tech Memo, NMFS-F/SPO-108, Silver Spring, MD

Nelson JA, Wilson RM, Coleman FC, Koenig CC, DeVries D, Gardner C, Chanton J (2012) Flux by fin: fish-mediated carbon and nutrient flux in the northeastern Gulf of Mexico. Mar Biol 159:365-372

> Nelson JA, Stallings CD, Landing W, Chanton J (2013) Biomass transfer subsidizes nitrogen to offshore food webs. Ecosystems 16:1130-1138

> Ney JJ (1993) Bioenergetics modeling today: growing pains on the cutting edge. Trans Am Fish Soc 122:736-748

Nye JA (2008) Bioenergetic and ecological consequences of diet variability in Atlantic croaker Micropogonias undulatus in Chesapeake Bay. PhD dissertation, University of Maryland, College Park, MD

Orth RJ, Heck KL Jr (1980) Structural components of eelgrass meadows in the lower Chesapeake Bay - fishes. Estuaries 3:278-288

Orth RJ, Heck KL Jr, van Montfrans J (1984) Faunal communities in seagrass beds: a review of the influence of plant structure and prey characteristics on predator-prey relationships. Estuaries 7:339-350

Orth RJ, Wilcox DJ, Whiting JR, Nagey L, Kenne AK, Smith ER (2013) 2012 Distribution of submerged aquatic vegetation in Chesapeake Bay and coastal bays. Special Scientific Report No. 155, Virginia Institute of Marine Science, Gloucester Point, VA

$>$ Pacheco AL (1962) Age and growth of spot in lower Chesapeake Bay, with notes on distribution and abundance of juveniles in the York River system. Chesap Sci 3: 18-28

Pattillo ME, Czapla TE, Nelson DM, Monaco ME (1997) Distribution and abundance of fishes and invertebrates in Gulf of Mexico estuaries, Vol 2: species life history summaries. Estuarine Living Marine Resources Report No. 2. NOAA/NOS Strategic Environmental Assessments Division, Silver Spring, MD

R Development Core Team (2013) R: a language and environment for statistical computing. R Foundation for Statistical Computing, Vienna

Rooker JR, Holt SA (1997) Utilization of subtropical seagrass meadows by newly settled red drum (Sciaenops ocellatus): patterns of distribution and growth. Mar Ecol Prog Ser 158:139-149

Rooker JR, Holt SA, Soto MA, Holt GJ (1998) Postsettlement patterns of habitat use by sciaenid fishes in subtropical seagrass meadows. Estuaries 21:318-327

> Rozas LP, Minello TJ (1997) Estimating densities of small fishes and decapod crustaceans in shallow estuarine habitats: a review of sampling design with focus on gear selection. Estuaries 20:199-213

Ryer C (1987) Temporal patterns of feeding by the blue crab Callinectus sapidus in tidal-marsh creek and adjacent seagrass meadow in the lower Chesapeake Bay. Estuaries 10:136-140

Schaffler JJ, van Montfrans J, Jones CM, Orth RJ (2013) Fish communities in seagrass nurseries of Chesapeake Bay are structured by abiotic and biotic factors and are vulnerable to climate change. Mar Coast Fish Dyn Manage Ecosyst Sci 5:114-124

Seitz RD, Wennhage H, Bergström U, Lipcius RN, Ysebaert $\mathrm{T}$ (2014) Ecological value of coastal habitats for commercially and ecologically important species. ICES J Mar Sci 71:648-665

Simpfendorfer CA, Bonfil R, Latour RJ (2005) Mortality estimation. In: Musick JA, Bonfil R (eds) Management techniques for elasmobranch fisheries. FAO Fisheries Technical Paper No 474. FAO, Rome

Smith N, Jones CM, van Montfrans J (2008) Historical patterns of growth in juvenile spotted seatrout. J Fish Biol 73:597-607

Sobocinski KL, Orth RJ, Fabrizio MC, Latour RJ (2013) Historical comparison of fish community structure in lower Chesapeake Bay seagrass habitats. Estuaries Coasts 36: 775-794

Sogard SM (1992) Variability in growth rates of juvenile fishes in different estuarine habitats. Mar Ecol Prog Ser 85:35-53

Sogard SM (1997) Size-selective mortality in the juvenile stage of teleost fishes: a review. Bull Mar Sci 60: 1129-1157

Stevens M, Maes J, Ollevier F (2006) A bioenergetics model for juvenile flounder Platichthys flesus. J Appl Ichthyology 22:79-84

> Stewart DJ, Weiningen D, Rottiers DV, Edsall TA (1983) An energetics model for lake trout, Salvelinus namaycush: application to the Lake Michigan population. Can J Fish Aquat Sci 40:681-698

Virnstein RW, Howard RK (1987) Motile epifauna of marine macrophytes in the Indian River lagoon, Florida. I. Comparisons among three species of seagrasses from adjacent beds. Bull Mar Sci 41:1-12

Waggy GL, Peterson MS, Comyns BH (2007) Feeding habits and mouth morphology of young silver perch (Bairdiella chrysoura) from the north-central Gulf of Mexico. Southeast Nat 6:743-751

Weinstein MP, Walters MP (1981) Growth, survival, and production in young-of-year populations of Leiostomus xanthurus Lacépède, residing in tidal creeks. Estuaries 4: 185-197

Werner EE, Gilliam JF (1984) The ontogenetic niche and species interactions in size-structured populations. Annu Rev Ecol Syst 15:393-425

Winberg GG (1956) Rate of metabolism and food requirements of fishes (Intensivnost obmena i pischevye petrebrosti ryb). Scientific Proceedings of the Belarusian State University, Lenin, Minsk (in Russian). Fish Res Board Can Transl Ser 194:1-202

Wood SN (2006) Generalized additive models: an introduction with R. CRC Press, Boca Raton, FL

Wuenschel MJ, Werner RG, Hoss DE (2004) Effect of body size, temperature, and salinity on the routine metabolism of larval and juvenile spotted seatrout. J Fish Biol 64: 1088-1102

> Wuenschel MJ, Jugovich AR, Hare JA (2006) Estimating the energy density of fish: the importance of ontogeny. Trans Am Fish Soc 135:379-385

Zuur AF (2013) A beginner's guide to generalized additive models with R. Highland Statistics, Newburgh

Zuur AF, Ieno EN, Walker NJ, Saveliev AA, Smith GM (2009) Mixed effects models and extensions in ecology with R. Springer, New York, NY 